\title{
Social, Emotional, and Behavioral Skills: An Integrative Model of the Skills Associated With Success During Adolescence and Across the Life Span
}

\author{
Christopher M. Napolitano ${ }^{1,2 *}$, Madison N. Sewell ${ }^{1}$, Hee J. Yoon ${ }^{3}$, Christopher J. Soto ${ }^{4}$ and \\ Brent. W. Roberts ${ }^{3,5}$ \\ ${ }^{1}$ Department of Educational Psychology, University of Illinois at Urbana-Champaign, Champaign, IL, United States, ${ }^{2}$ Department \\ of Psychology, University of Zurich, Zurich, Switzerland, ${ }^{3}$ Department of Psychology, University of Illinois at Urbana-Champaign, \\ Champaign, IL, United States, ${ }^{4}$ Department of Psychology, Colby College, Waterville, ME, United States, ${ }^{5}$ Hector Research \\ Institute of Education Sciences and Psychology, University of Tübingen, Tübingen, Germany
}

Social, emotional, and behavioral (SEB) skills encompass a wide range of competencies related to how individuals build and maintain relationships, understand and manage emotions, pursue goals, and learn from experience. Despite near-consensus on the importance of SEB skills for success in life, there are numerous frameworks that simultaneously converge and diverge in how they define and measure SEB skills. In this article, we discuss our integrative model encompassing five broad skill domains: SelfManagement, Innovation, Social Engagement, Cooperation, and Emotional Resilience Skills (Soto et al., 2021a). Our model defines SEB skills as skills (i.e., what someone is capable of doing) and not traits (i.e., what someone tends to do). Using this definition and model as a foundation, we argue for the importance of investigating SEB skill development during adolescence, a period where SEB skills may be both particularly amenable to change and particularly predictive of life outcomes. In particular, we highlight how SEB skills allow adolescents to take advantage of the new opportunities afforded to them as they make major cognitive and social transitions.

Keywords: social, emotional, and behavioral skills, socioemotional skills, adolescence, social and emotional learning (SEL), big five

\section{INTRODUCTION}

A person's successful development is multicausal. No one factor, whether at the biological, psychological, social, or historical levels, guarantees a person's positive development. Nevertheless, researchers have long sought to identify the individual characteristics that can alter a person's chances for positive development. In recent years, this search has led scholars across the social sciences to investigate the nature, structure, assessment, and correlates of a broad range of personal qualities, sometimes termed noncognitive skills, character strengths, socioemotional competencies, or social, emotional, and behavioral (SEB) skills (Soto et al., 2021b). These constructs hold promise as potential predictors of positive development. Many studies have demonstrated their associations with positive development, and there is some evidence suggesting their malleability (Duckworth et al., 2007; Durlak et al., 2011; Heckman and Kautz, 2012; Kautz et al., 2014; Nagaoka et al., 2015; National Research Council, 2012; OECD, 2015; Taylor et al., 2017). 
But beneath this promise, fundamental issues of conceptualization and measurement remain. There is no consensus as to what these personal qualities are and what they are not. There is also no consensus taxonomy of personal qualities, nor is there a consensus of these qualities' developmental characteristics. We believe that the field's ability to best understand and promote positive development requires placing some "stakes in the ground" that begin to delineate a shared path forward.

We aim to build toward consensus in this field by providing our responses to four key questions. First, how should the personal qualities that predict positive development be conceptualized? We argue that these qualities are best understood as skills and not traits. We define SEB skills as a person's capacities to maintain social relationships, regulate emotions, and manage goal- and learning-directed behaviors (Soto et al., 2021a). Second, how can the wide range of SEB skills be taxonomized? We argue the behaviors included in the Big Five personality domains provide a comprehensive foundation for a skills-based taxonomy that is both conceptually and empirically justifiable. Third, how should SEB skills be measured? We argue that self- and observer-reported skills inventories are optimal. Fourth, is there a period of the life span that holds particular promise for SEB skills research and interventions? We argue for adolescence as a focal period for SEB skills research.

\section{HOW SHOULD THE PERSONAL QUALITIES THAT PREDICT POSITIVE DEVELOPMENT BE DEFINED AND CONCEPTUALIZED?}

At present, most reviews in this broad literature begin similarly: by listing the historical evolution and the contemporary abundance of terms used to describe the field (e.g., soft skills, social and emotional skills, character strengths) (National Research Council, 2012; Duckworth and Yeager, 2015; Berg et al., 2017; Abrahams et al., 2019). A grasp of the field's history does provide valuable context. But we encourage readers to look past the differences in existing and historical terms for the personal qualities associated with success in life, and instead focus on the similarities and differences in the way most of these terms are conceptualized. Regarding similarities, Duckworth and Yeager (2015) noted that the various terms in this literature tend to share five core features: These personal qualities are conceptualized to be 1) beneficial to a person and their social partners; 2) expressed most clearly in relevant situations; 3) distinct from measured intelligence; 4) somewhat stable over time; but also 5) malleable, or potentially responsive to interventions (Duckworth and Yeager, 2015).

These similarities seem a reasonable starting point from which to build consensus. However, this "big tent" includes an extremely broad range of personal qualities that can include beliefs, attitudes, values, motivations, personality traits, and skills. From our vantage, this inclusivity actually stifles opportunities to come to conceptual or measurement consensus. Thus, as a first stake in the ground, we recently suggested shifting the field's focal length from a broad and inclusive set of personal qualities to, more narrowly, SEB skills, which we defined as capacities to maintain social relationships, regulate emotions, and manage goal- and learning-directed behaviors (Soto et al., 2021b).

Our conceptualization adds two important distinctions to Duckworth and Yeager's core features. First, SEB skills are not traits, or a person's "average" or "typical" behavior in a domain. We intentionally define SEB skills as capacities, or how someone is capable of behaving when the situation calls for it (Paulhus and Martin, 1987; Wallace, 1966, Wallace, 1967) ${ }^{1}$. This distinction recalls early work in personality and applied psychology that distinguished between typical and maximal performance of behavior (Sackett et al., 1988; Turner, 1978). In making this distinction, we are not arguing that traits do not relate with people's relationships, emotions, goals, and learning; they certainly do. Nor do we argue that skills should replace traits as predictors of positive development. Instead, we propose that traits and skills may predict different aspects of positive development or predict positive development in different ways. A second added component of our definition is that it delineates the broad categories of capacities that can be considered SEB skills. In our conceptualization, SEB skills encompass a diverse set of behaviors that include, for example, how people socially interact and collaborate, how they manage and modulate their emotions, and how they work toward accomplishing shorterterm tasks and longer-term goals.

Why introduce a new term in "social, emotional, and behavioral skills" when others already proliferate? Researchers, practitioners, policymakers, and the general public will ultimately decide which term best captures this domain. However, we believe that the term SEB skills provides some benefit in that it integrates two bodies of research that have developed concurrently across the last several decades. Acknowledging the work of developmental psychologists and educational researchers, SEB skills incorporates the "social and emotional" terminology common in those fields. Similarly, the "behavioral" component SEB skills acknowledges the work of personality and motivational psychologists, as well as economists, who have suggested that a constellation of skills or actions related to self-regulation, self-control, and conscientiousness are malleable and play a critical role in predicting positive life outcomes (Almlund et al., 2011; Heckman and Kautz, 2012; Kautz et al., 2014; Scorza et al., 2016). Finally, we intentionally chose the word "skill" both to emphasize that these attributes are malleable, trainable capacities (rather than fixed traits) and because it is colloquial and accessible to researchers, practitioners, and the general public.

\footnotetext{
${ }^{1}$ We note here that others in the field sometimes use the term "capacity" to refer to what we term traits (e.g., see Keizer et al., 2019 for a useful perspective on self-
} reliance). 
TABLE 1 | Aligning prominent taxonomies of competencies, character strengths, and skills.

\begin{tabular}{|c|c|c|c|c|c|}
\hline BESSI domains & $\begin{array}{l}\text { Social engagement } \\
\text { Skills }\end{array}$ & $\begin{array}{l}\text { Cooperation } \\
\text { Skills }\end{array}$ & $\begin{array}{l}\text { Self-management } \\
\text { Skills }\end{array}$ & $\begin{array}{l}\text { Emotional Resilience } \\
\text { skills }\end{array}$ & Innovation Skills \\
\hline 21st century competencies & \multicolumn{2}{|c|}{ Interpersonal competencies } & \multicolumn{2}{|c|}{ Intrapersonal competencies } & $\begin{array}{c}\text { Cognitive } \\
\text { competencies }\end{array}$ \\
\hline Five Cs of positive youth & Connection & Caring & Competence & Confidence & \\
\hline development & \multicolumn{4}{|c|}{ Character* } & \\
\hline \multicolumn{6}{|c|}{ Responsible decision-making ${ }^{\star}$} \\
\hline OECD framework & Engagement with others & Collaboration & Task performance & Emotion regulation & Open-mindedness \\
\hline
\end{tabular}

\section{HOW CAN THE WIDE RANGE OF POSSIBLE SOCIAL, EMOTIONAL, AND BEHAVIORAL SKILLS BE TAXONOMIZED?}

Just as there are many terms for constructs related to SEB skills, there are also many (at least 136; Berg et al., 2017) different frameworks or taxonomies for organizing specific personal attributes within broader domains. Prominent frameworks for constructs that are conceptually-adjacent to SEB skills include, for example, the National Research Council's 21st Century competencies, CASEL's Framework for Social and Emotional Learning, the OECD's Framework for Social and Emotional Skills, and the Lerner and Lerner's Five Cs Model of Positive Youth Development ${ }^{2}$. These prominent taxonomies of SEB skills are compared and contrasted (relative to our proposed taxonomy, described later) in Table 1.

The similarities across models in Table $\mathbf{1}$ provide some footholds toward taxonomic consensus. For one, in balancing the needs to capture a broad range of skills while also remaining intuitive and parsimonious, attribute taxonomies tend to include three to five domains. Moreover, the included domains overlap considerably across taxonomies in their psychological content. Among three-domain models, the 21st century competencies taxonomy and the character strengths taxonomy provide an illustrative example. Both models include three skill domains, labeled as "intrapersonal," "interpersonal," and "cognitive" or "intellectual" capacities or strengths. Prominent five-domain taxonomies are also often characterized by considerable overlap. For example, the CASEL taxonomy differentiates interpersonal capacities into two domains: those for setting and pursuing goals (self-management competencies), and those for understanding one's attitudes, values, and emotions (self-awareness competencies). Similarly, the Five Cs taxonomy breaks down intrapersonal capacities into those used to achieve goals in life domains important to youth, like school, work, and athletics (competence skills), and those youth use to support their emotions, motivation, and values (confidence skills).

${ }^{2}$ For those interested in comparing the various frameworks in detail, we suggest the useful "Explore SEL" web resource by Stephanie Jones and the EASEL lab (easel. gse.harvard.edu).
But there are also important differences across taxonomies. Some of these issues are conceptual: existing taxonomies sometimes focus on one type of personal quality (e.g., the OECD taxonomy is comprised of only traits), whereas others include multiple types like skills, traits, attitudes, values, and more. Other differences are structural: some frameworks are composed of superordinate attribute domains alone (e.g., the 5Cs model). Among those taxonomies that do include subordinate attributes or "facets," there is variation in these attributes' number and content.

\section{Using the Big Five Personality Domains to Taxonomize Social, Emotional, and Behavioral Skills}

If there are already over one hundred taxonomies for SEB skills and related concepts, then why introduce another? We have two motivations. First, we believe that a consensus taxonomy should be comprehensive, accounting for the wide range of skills associated with success. Second, a consensus taxonomy should be evidence-based, deriving from an expansive body of research that informs its structure and guides future research. Work in each of the existing frameworks has made meaningful contributions, but in our view, none fully satisfies both conditions.

We have proposed that SEB skills can be organized in terms of five broad domains informed by the Big Five personality traits (Soto et al., 2021a), an organizational framework that we believe satisfies both conditions stipulated above. Relevant to the requirement of comprehensiveness, the Big Five provide a wide-ranging conceptual and empirical framework for studying human behavior. Behaviors associated with Conscientiousness and Openness to Experience relate to educational and occupational attainment (Heckman and Kautz, 2012; Noftle and Robins, 2007; Wilmot and Ones, 2019). Behaviors relevant to the Extraversion and Agreeableness domains are associated with a wide range of interpersonal behaviors (DeYoung et al., 2013; McCrae and Costa, 1989). Similarly, Extraversion and Emotional Stability capture key characteristics of a person's emotional life (i.e., positive and negative affect; Diener et al., 2003). 


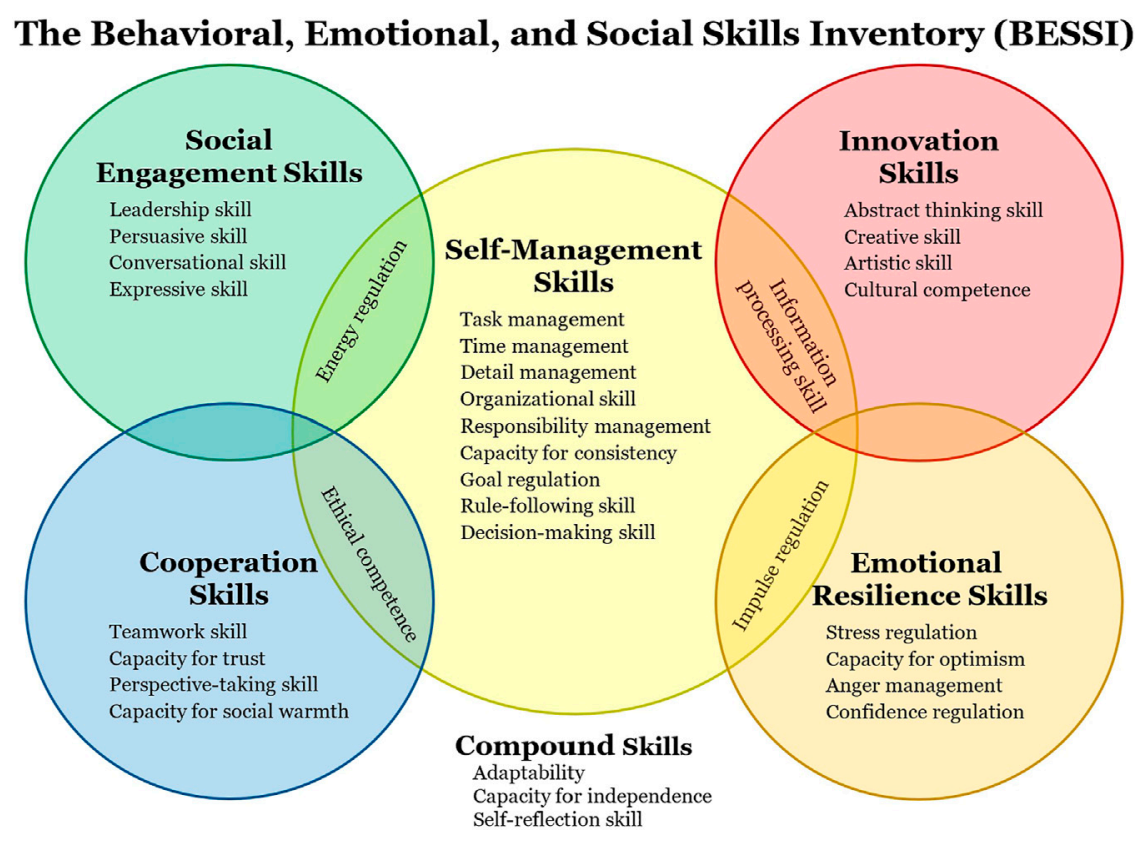

FIGURE 1 | A proposed domain-level taxonomy of SEB skills.

The Big Five also provide a sufficient evidence base. Research spanning early childhood through old age (Allemand et al., 2008; Roberts and Mroczek, 2008; Shiner and DeYoung, 2013; Soto and Tackett, 2015) has demonstrated that the Big Five constitute a useful taxonomy for summarizing people's characteristic thoughts, feelings, and behaviors across a wide range of global cultural contexts (Saucier and Goldberg, 2001; Schmitt et al., 2007; De Raad et al., 2010). We therefore argue that work on SEB skills can usefully adapt this taxonomy by replacing a trait-based conceptualization with one that is skills-based, while using the same behavioral referents. We further propose that this taxonomy's research base can stimulate a vibrant set of research questions and hypotheses regarding how skills and traits are similar or different in terms of their structure, assessment, development, and outcomes.

In general, we hypothesize that skills and traits sharing the same behavioral referents are positively correlated, due to these common referents as well as the developmental interplay of experience, skill, and disposition. For example, consider leadership. Many adolescents may lack meaningful leadership experience. Nonetheless, if given the proper training, their capacity or skill to lead would be enhanced, even if their proclivity for leadership were lacking. Once armed with the capacity to lead and then given the opportunity to lead as they age, people first relying on their skill could then develop the habitual propensity toward effective leadership, manifest in traits such as assertiveness combined with thoughtful consideration. Conversely, it may be that someone who is dispositionally wellsuited for leadership (e.g., high extraversion and agreeableness) chooses or selects leadership experiences that leads to skill development. Despite these strong links, traits and skill can still be differentiated from each other. Consider a person in a leadership position who struggles to actually lead their team (high trait, low skill) or the usually-introverted person who, in a moment of crisis, emerges from their typical support role to lead their team (low trait, high skill).

To begin addressing the developmental interplay of skills and traits, as well as other critical questions, we have developed a conceptual and assessment framework of 32 specific SEB skills arrayed across five domains, and examined these skills' points of convergence and divergence with alternative models of strengths, competencies, and traits (Soto et al., 2021a; Soto et al., 2021b). Conceptually, the five domains of SEB skills we propose include:

1 Social Engagement Skills: capacities used to actively engage with other people (cf. Extraversion);

2 Cooperation Skills: capacities used to maintain positive social relationships (cf. Agreeableness);

3 Self-Management Skills: capacities used to effectively pursue goals and complete tasks (cf. Conscientiousness);

4 Emotional Resilience Skills: capacities used to regulate emotions and moods (cf. Emotional Stability vs. Neuroticism); 5 Innovation Skills: capacities used to engage with novel ideas and experiences (cf. Openness to Experience).

Table 1 compares our domain-level taxonomy to other prominent taxonomies. Figure 1 provides a visual depiction of our proposed taxonomy, including the individual skill facets. The five SEB skills domains we propose are not rigid, exclusive categories. Our system includes interstitial and compound skills at the intersection of two or more broad domains. We also do not assume at this juncture that our list of 32 facets is complete, and expect that future research will reveal more skills and some reorganization of the overall structure. 


\section{HOW SHOULD SOCIAL, EMOTIONAL, AND BEHAVIORAL SKILLS BE MEASURED?}

To this point, we have argued that SEB skills represent a promising focal point for conceptualizing the personal qualities associated with success. We have also argued that SEB skills can be organized in terms of five broad domains that resemble the Big Five in terms of their social, emotional, and behavioral referents, but are defined as sets of functional capacities rather than traits. We now consider issues of measurement.

At present, a common approach to measuring these attributes is to use the questionnaire format of a personality inventory. These measures commonly use adjectives, phrases, or statements describing behavioral tendencies (e.g., "I got my work done right away instead of waiting until the last minute"). Participants rate how well each item describes their own tendencies, often using a Likert-type format (e.g., Primi et al., 2016; Park et al., 2017). There are advantages to this approach. Personality inventories can be reliable and valid indicators of thoughts, feelings, motivations, and behaviors (Wilt and Revelle, 2015). Many participants in Western contexts have encountered such measures before and administering the items is cost-effective (Mehl et al., 2006; Vazire, 2006; John and Soto, 2007).

However, items based in this approach are not ideally suited for our capacities-based conceptualization of SEB skills: they assess a person's traits more so than their skills (Paulhus and Martin, 1987; Wallace, 1966, Wallace, 1967). Said differently, a trait approach would measure a person's "mean" level of a particular SEB skill, rather than their "maximal" level or capacity.

We believe that one promising way to efficiently assess capacities are to use skill inventories: questionnaire measures in which each item represents a specific social, emotional, or behavioral skill, and respondents rate their own capacity (or the capacity of a target individual, for observer-reports) to perform that skill when called upon to do so (Wallace, 1966, Wallace, $1967)^{3}$. Other researchers in this domain have adopted a similar approach. For example, researchers and educators developed preliminary skill-inventory scales to measure the CASEL competencies of relationship skills, social awareness, selfawareness, self-management, and responsible decision-making (Davidson et al., 2018). Thus, consistent with others, we argue that skill inventories represent a conceptually consistent, reliable, valid, and efficient means to assess SEB skills.

To put this argument into practice and build on the conceptual model illustrated in Table $\mathbf{1}$ and Figure 1, our research team and an international group of colleagues has developed a broadband skills inventory based on our proposed five-domain model of SEB skills: the Behavioral, Emotional, and Social Skills Inventory (BESSI; Soto et al., 2021a). Across a series of seven samples of

\footnotetext{
${ }^{3}$ We note that other approaches to measuring skills are also plausible, such as using situational judgement tests or behavioral tasks. Each approach has strengths and drawbacks. Skills inventories adopt a familiar format for participants, they are costeffective to administer, and in the case of our early research, seem to have acceptable psychometric characteristics.
}

self-reports and observer-reports $(N=6,309)$, we find that the BESSI provides reliable and valid assessment of SEB skill domains and facets. Across these samples, reliability estimates averaged approximately 0.95 for the BESSI's five major skill domains, and 0.85 for its 32 more-specific skill facets. The BESSI's measurement structure was adequately modeled by a combination of 5 domainlevel and 32 facet-level factors (CFI and TLI $\geq 0.93$, RMSEA and SRMR $\leq 0.04)$. The BESSI skill domains and facets converged meaningfully with existing measures of character and developmental strengths, as well as social and emotional learning competencies, while also providing incremental validity beyond the Big Five personality traits (Mean $\Delta R^{2}=$ 0.10). Moreover, in a longitudinal study of high school students, they concurrently and prospectively predicted a range of consequential outcomes including academic achievement and engagement, occupational interests, social relationships, and well-being.

\section{IS THERE A DEVELOPMENTAL PERIOD THAT HOLDS PARTICULAR PROMISE FOR SOCIAL, EMOTIONAL, AND BEHAVIORAL SKILLS RESEARCH AND INTERVENTIONS?}

Having proposed our definition and taxonomy for SEB skills and proposed an optimal way to measure these skills, we turn to our last question: Is there a period of the life span that holds particular promise for SEB skills research and interventions? We argue that adolescence ought to be the focal period of SEB skills research. Our rationale is based in decades of psychological science research indicating that adolescence is a period of marked transitions across multiple domains, and that in order to successfully navigate those transitions, youth must use a wide range of complex, newly developing skills.

\section{Developmental Characteristics of Adolescence That Social, Emotional, And Behavioral Skills Development and Importance}

Adolescence begins with the onset of puberty-the biological transition to physical maturity. Puberty has been described as a cascade of neurobiological effects that influence growth, metabolic changes, and sexual maturation (Dahl et al., 2018). Beyond puberty's influence on physical development, changes in structure and function in the brain during puberty spur the cognitive advances that differentiate adolescent cognition from child cognition. For example, significant synaptic pruning and more focused activation in the prefrontal cortex enhance adolescents' self-management and executive functioning capabilities (Blakemore and Choudhury, 2006; Blakemore,

\footnotetext{
${ }^{2}$ For those interested in comparing the various frameworks in detail, we suggest the useful "Explore SEL" web resource by Stephanie Jones and the EASEL lab (easel. gse.harvard.edu).
} 
TABLE 2 | SEB skills in relation to new adolescent developmental abilities and opportunities.

\begin{tabular}{|c|c|c|c|}
\hline SEB skill & SEB skill definition & Developmental ability & Developmental opportunity \\
\hline $\begin{array}{l}\text { Perspective- } \\
\text { taking }\end{array}$ & $\begin{array}{l}\text { Capacity to understand other people's thoughts } \\
\text { and feelings }\end{array}$ & Greater awareness of others emotional states & Intimate interpersonal relationships \\
\hline Abstract thinking & Capacity to engage with abstract ideas & Advances in moral and prosocial reasoning & Civic engagement \\
\hline Impulse control & Capacity to intentionally inhibit impulses & Enhanced planning and self-regulation capabilities & $\begin{array}{c}\text { Development and maintenance of healthy } \\
\text { habits }\end{array}$ \\
\hline Goal regulation & $\begin{array}{l}\text { Capacity to set clear and ambitious goals for } \\
\qquad \text { oneself }\end{array}$ & $\begin{array}{l}\text { Increases in future orientation and self-regulation } \\
\text { capabilities }\end{array}$ & Achievement in education and in career \\
\hline
\end{tabular}

2012). Additional changes in the "social brain" allow adolescents to become more aware of social cues, more sensitive to others' emotional states, and more cognizant of their own social standing (Blakemore and Choudhury, 2006; Pfeifer and Blakemore, 2012; Pfeifer et al., 2013).

Though the transition to physical maturity is a hallmark of adolescence, it is not the only transition that adolescents make. The end of adolescence is also marked by the transition to adult social roles, responsibilities, and status. Key developmental tasks of adolescence include completing education, choosing a career, finding a romantic partner, developing healthy habits, establishing close friendships, and getting involved in one's community. We will review these cognitive and social transitions to demonstrate how many SEB skills are both newly possible and newly critical for adolescents, relative to younger children.

Table 2 provides a guide for our review, highlighting four example SEB skills, their developmental underpinnings within the cognitive transitions of adolescence, and accompanying developmental opportunities during adolescent social transitions. This table does not encompass every relationship between developmental changes, SEB skills, and developmental opportunities. Successful development is multicausal, so while we only list one example SEB skill as relevant to each developmental task, adolescents likely utilize a constellation of SEB skills. Further, the four skills we highlight here have a clear origin within the cognitive transitions of adolescence, making these skills "possible," as well as clear social implications, making them "critical."

\section{Cognitive Transitions}

The cognitive advances of adolescence are rooted in the neurobiological changes of puberty. Significant work within the field of developmental neuroscience has connected changes in structure and function of the brain and connectivity between regions of the brain to the more complex and abstract thinking capabilities, self-management capabilities, and relational thinking capabilities of adolescent cognition. In this section, we will briefly review the newly prominent adolescent cognitive capabilities that correspond to the emergence of the following SEB skills: 1) perspective-taking skill, 2) abstract thinking skill, 3) impulse regulation, and 4) goal regulation.

We define perspective-taking skill as the capacity to understand other people's thoughts and feelings, and numerous findings over the past decade underscore that perspective-taking capacities increase and gain importance during adolescence. For example, adolescents are better able to recognize subtle changes in others' facial expressions compared to children (Garcia and Scherf, 2015; Kragel et al., 2015), and adolescents are more cognizant of others' mental states (Masten et al., 2009; Pfeifer and Blakemore, 2012). Further, as adolescents grow older, othersoriented reasoning becomes more prominent (Crone, 2013), highlighting that adolescents incorporate the thoughts and feelings of others in their decision-making processes.

Also relevant to adolescents' decision-making processes is abstract thinking skill, the capacity to engage with abstract ideas. Compared to children, adolescents can critically engage with abstract topics such as politics and religion, and think in relativistic terms (Kuhn, 2009; Smetana and Villalobos, 2009). These advances in cognition lead to more complex moral reasoning skills. While children tend to justify moral decisions in terms of rewards and punishments, adolescents began to view moral decisions in terms of societal conventions or abstract principles such as equity or the sanctity of human life (Eisenberg et al., 2009; Kohlberg, 1987).

Finally, impulse regulation, the capacity to intentionally inhibit impulses, and goal regulation, the capacity to set clear and ambitious goals for oneself, have a robust body of work linking these self-management capacities to structural and functional changes in the prefrontal cortex during adolescence (Casey et al., 2008). Impulse regulation demonstrates linear growth across adolescence with older adolescents better able to resist temptations than younger adolescents (Duckworth and Steinberg, 2015). Further, adolescents are able to think about what is possible, not just what is real, and think about the longterm consequences of their decisions (Nurmi, 2004; Beck and Riggs, 2014). Advances in planning and self-management, in addition to increases in future orientation, permit the setting and striving for goals (Napolitano et al., 2011a). In the next section, we highlight how these specific skills gain importance as adolescents face new developmental opportunities and challenges.

\section{Social Transitions}

Adolescence ends with the complete transition to adult social roles-a boundary difficult to pinpoint as it is subject to variability across domains, cultures, and historical periods (e.g., an American 18 year old serving in the armed forces but forbidden from purchasing alcohol). The emergence of a wide range of SEB skills help adolescents to successfully transition to adult status, roles, and responsibilities. In this section, we feature perspective-taking skill, abstract thinking skill, impulse regulation, and goal regulation in relation to four key 
developmental opportunities and challenges that exemplify the transition to adult roles: 1) establishing intimate relationships, 2) engaging with the larger community, 3) developing and maintaining healthy habits, and 4) planning for postsecondary education and a career.

\section{Establishing Intimate Relationships}

Interpersonal relationships, particularly with peers, are central to the adolescents' lives. These relationships satisfy multiple roles within the context of adolescent development including serving as socializing agents, as emotional and social support, and as establishing the context of the social hierarchy (Ryan and Shin, 2018). The quality of relationships with peers, parents, and important others is related to immediate benefits in the lives of adolescents such as better grades, psychosocial adjustment, and social skills and long-term benefits as they set the stage for future friendships and romantic partnerships (Connolly et al., 2000; Glick and Rose, 2011; Arnold et al., 2017; Ryan and Shin, 2018).

We argue that use of perspective-taking skill during adolescence leads to more intimate and fulfilling relationships with friends and family. For example, imagine a conflict between two best friends in which one friend posted an unflattering picture of the other on social media. Even if the "poster" didn't think that the picture is a bad picture of their friend, they could use their perspective-taking skill to see the situation from their best friend's point of view, accept their friend's request to take down the picture, and reconcile with their friend. This skill use could therefore help resolve the conflict and preserve the friendship.

\section{Engaging With the Larger Community}

As adolescents develop intimate relationships with others, they also develop a more sophisticated understanding of their relationship with people in their community and society at large. The use of abstract thinking skill in tandem with advances in moral and prosocial reasoning enables adolescents to think critically and deeply about their role within the larger community. While advances in moral and prosocial reasoning do not always lead to increases in moral or prosocial behaviors (Eisenberg et al., 2009; Wray-Lake et al., 2016), abstract thinking skill may help promote civic engagement in adolescence via the integration of abstract values, such as altruism and civic responsibility into their attitudes and identity.

Supporting these possible links between civic engagement, abstract thinking skill, attitude, and identity, cross-cultural research on youth civic engagement has found associations between normative beliefs about good citizenship and intentions to vote and volunteer (Metzger and Smetana, 2010). Other studies have indicated that volunteers tend to be more altruistic than non-volunteers (Eisenberg et al., 2009) and that having a helping identity mediates the relationship between demographic characteristics, personality, and volunteering (Matsuba et al., 2007). Abstract thinking skill may be especially important when adolescents are faced with information that contradicts their worldview. For example, an adolescent who is apathetic about their obligatory service learning project in school may change their opinion on service when they learn more about issues facing their community. Thinking deeply about what they learned during their service learning project and the question of whether they live in a fair and just society may foster a greater desire to participate in future civic engagement to improve their community.

\section{Developing and Maintaining Healthy Habits}

Civic engagement becomes a developmental opportunity during adolescence not only because of advances in cognition and abstract thinking skill, but also because adolescents have more autonomy to direct their behavior. Many scholars have focused their attention on self-management capacities, particularly in youth, because adolescents increasingly make their own decisions. For example, adolescents must leverage their impulse regulation skills when they have to make a choice between doing homework while resisting the urge to check social media or choosing a nutritious snack over junk food.

Indeed, a developmental challenge of adolescence is to establish and maintain healthy habits such as eating a balanced diet, exercising regularly, getting enough sleep, and avoiding smoking. These health behaviors are not only related to shortterm benefits for adolescents, but also influence the course of adult habits (Hallal et al., 2006). Impulse regulation may be especially important for adolescents who are beginning a transition to healthier habits. For instance, an adolescent who spends the majority of their time doing sedentary activities may decide to begin exercising to boost their confidence. As they begin a workout regime, they may feel very tempted to skip a few workouts because they recently got a new video game. However, with maximum effort, they keep to their exercise routine. Honing a skill related to resisting and avoiding temptations may be particularly important for adolescents with high sensitivity to rewards and sensationseeking (Casey et al., 2008; Duckworth and Steinberg, 2015).

\section{Planning for Post-Secondary Education and a Future Career}

For many adolescents, the most salient task is achievement, and significant research has investigated how an adolescent's personal qualities (Komarraju and Nadler, 2013; Poropat, 2009), relationships (Ryan and Shin, 2018), civic engagement (Ballard et al., 2019), and health behaviors (Bradley and Green, 2013) relate to educational attainment and socioeconomic status in adulthood. As adolescents approach the transition from school to the workforce, they begin to define themselves and direct their own development through their goals (Napolitano et al., 2011b; Nurmi, 2004; Salmela-Aro, 2009). For example, several studies have linked adolescents' educational and career aspirations and expectations to their educational and vocational outcomes (Brumley, et al., 2019; Lent et al., 2000; Salmela-Aro, 2009). Aspirations and expectations serve as a first step toward a goal but do not ensure goal attainment. Goal regulation might be particularly important in the face of setbacks. An American adolescent who aspires to attend a competitive university may question their capabilities when they receive a lower-thanexpected score on a college entrance exam. However, drawing on their goal regulation capabilities, they make a study plan to better prepare for the next test date. 


\section{The Importance of Adolescence Vs. Early Childhood for Social, Emotional, and Behavioral Skills}

We have highlighted the potential importance of adolescence for the malleability and real-world implications of SEB skills. An alternative view could assert early childhood's importance for the development of SEB skills. From this perspective (termed a "gradualist" approach, see Lewis, 1998), one could argue that the SEB skills necessary for successful development during adolescence are built upon foundational skills that emerge during early childhood (e.g., executive functions, Diamond, 2013). Therefore, interventions should focus on promoting the development of these foundational skills early in life. For example, economists have used a "return on investment" framework to argue for the benefits of skill interventions for young children (e.g., Heckman and Kautz, $2012{ }^{4}$ ). A notable empirical example of such work involves the Perry Preschool Program, which provided evidence that a high-quality preschool altered disadvantaged 3-4 year old's personality traits, positively impacting future outcomes like standardized test scores (Heckman et al., 2010a; Heckman et al., 2010b).

We do not dispute or discount the results of these studies. The sustained effects of early-childhood interventions on the antecedents of some SEB skills may indeed "cascade" into adolescence. Nor are we suggesting that early-childhood education is unimportant, or that early experiences do not impact later functioning and development. However, we believe that carefully-timed interventions for adolescents that target the precise SEB skills needed to meet a critical challenge may, in some cases, be more effective than interventions with young children targeting the foundational developmental antecedents of those same skills. As a concrete example, 18 year-olds' scores on standardized tests may be improved

\section{REFERENCES}

Abrahams, L., Pancorbo, G., Primi, R., Santos, D., Kyllonen, P., John, O. P., et al. (2019). Social-emotional Skill Assessment in Children and Adolescents: Advances and Challenges in Personality, Clinical, and Educational Contexts. Psychol. Assess. 31 (4), 460-473. doi:10.1037/pas0000591

Allemand, M., Zimprich, D., and Martin, M. (2008). Long-term Correlated Change in Personality Traits in Old Age. Psychol. Aging 23 (3), 545-557. doi:10.1037/ a0013239

Almlund, M., Duckworth, A. L., Heckman, J., and Kautz, T. (2011). Personality Psychology And Economics (No. W16822). National Bureau of Economic Research. doi:10.3386/w16822

Arnold, A. L., Lucier-Greer, M., Mancini, J. A., Ford, J. L., and Wickrama, K. A. S. (2017). How Family Structures and Processes Interrelate. J. Fam. Issues 38 (6), 858-879. doi:10.1177/0192513X15616849

Ballard, P. J., Hoyt, L. T., and Pachucki, M. C. (2019). Impacts of Adolescent and Young Adult Civic Engagement on Health and Socioeconomic Status in Adulthood. Child. Dev. 90 (4), 1138-1154. doi:10.1111/cdev.12998

${ }^{4}$ Others have more recently made the case for adolescence as important periods (e.g., Kautz and Zanoni, 2014). more by an intervention promoting their studying-related SEB skills in the months prior to the test than by a longer-term intervention on their executive functions in preschool, thirteen years prior. We therefore believe that a program of research comparing the effects of SEB skills interventions during adolescence and early childhood, both in terms of return-oninvestment and developmental benefits, is a critical frontier of this burgeoning field.

\section{CONCLUSION}

We argued that social, emotional, and behavioral (SEB) skills are best conceptualized as skills, what a person is capable of doing when the situation calls for it, and not traits, what a person tends to do across situations. We also presented a comprehensive and evidence-based taxonomy of SEB skills-the Behavioral, Emotional, and Social Skills Inventory (BESSI) - which organizes 32 SEB skills within a five-domain framework. To measure the 32 SEB skills within the BESSI framework, we advanced self- and observer-reported skills inventories as optimal for capturing maximum levels of skill utilization. Finally, we argued that future SEB skill research should focus on adolescence, a developmental period characterized by biological, cognitive, and social transitions that make the development SEB skills possible and makes the utilization of these SEB skills critical.

\section{AUTHOR CONTRIBUTIONS}

All authors contributed to the concepts and theories presented in this work. CN planned the manuscript. CN and MS provided a first draft and finalized the manuscript. CS, BR, and HY provided key edits and revisions to the manuscript.
Beck, S. R., and Riggs, K. J. (2014). Developing Thoughts about what Might Have Been. Child. Dev. Perspect. 8 (3), 175-179. doi:10.1111/cdep.12082

Berg, J., Osher, D., Same, M. R., Nolan, E., Benson, D., and Jacobs, N. (2017). Identifying, Defining, and Measuring Social and Emotional Competencies: Final Report. American Institutes for Research. Available at: https://www.air.org/resource/ identifying-defining-and-measuring-social-and-emotional-competencies.

Blakemore, S.-J., and Choudhury, S. (2006). Development of the Adolescent Brain: Implications for Executive Function and Social Cognition. J. Child. Psychol. Psychiat 47 (3-4), 296-312. doi:10.1111/j.1469-7610.2006.01611.x

Blakemore, S.-J. (2012). Imaging Brain Development: The Adolescent Brain. NeuroImage 61 (2), 397-406. doi:10.1016/j.neuroimage.2011.11.080

Bradley, B. J., and Greene, A. C. (2013). Do Health and Education Agencies in the United States Share Responsibility for Academic Achievement and Health? A Review of 25 Years of Evidence about the Relationship of Adolescents' Academic Achievement and Health Behaviors. J. Adolesc. Health 52 (5), 523-532. doi:10.1016/j.jadohealth.2013.01.008

Brumley, L. D., Russell, M. A., and Jaffee, S. R. (2019). College Expectations Promote College Attendance: Evidence from a Quasiexperimental Sibling Study. Psychol. Sci. 30 (8), 1186-1194. doi:10.1177/0956797619855385

Casey, B. J., Getz, S., and Galvan, A. (2008). The Adolescent Brain. Dev. Rev. 28 (1), 62-77. doi:10.1016/j.dr.2007.08.003

Chernyshenko, O. S., Kankaraš, M., and Drasgow, F. (2018). Social and Emotional Skills for Student success and Wellbeing: Conceptual Framework for the OECD Study on Social and Emotional Skills. Available at: https://www.oecd-ilibrary. 
org/education/social-and-emotional-skills-for-student-success-and-wellbeing_db1d8e59-en. doi:10.1787/db1d8e59-en

Collaborative for Academic, Social, and Emotional Learning (2020). SEL: What Are the Core Competence Areas and where Are They Promoted?. Available at: https://casel.org/core-competencies.

Connolly, J., Furman, W., and Konarski, R. (2000). The Role of Peers in the Emergence of Heterosexual Romantic Relationships in Adolescence. Child. Dev. 71 (5), 1395-1408. doi:10.1111/1467-8624.00235

Crone, E. A. (2013). Considerations of Fairness in the Adolescent Brain. Child. Dev. Perspect. 7 (2), 97-103. doi:10.1111/cdep.12022

Dahl, R. E., Allen, N. B., Wilbrecht, L., and Suleiman, A. B. (2018). Importance of Investing in Adolescence from a Developmental Science Perspective. Nature 554 (7693), 441-450. doi:10.1038/nature25770

Davidson, L. A., Crowder, M. K., Gordon, R. A., Domitrovich, C. E., Brown, R. D., and Hayes, B. I. (2018). A Continuous Improvement Approach to Social and Emotional Competency Measurement. J. Appl. Dev. Psychol. 55, 93-106. doi:10.1016/j.appdev.2017.03.002

De Raad, B., Barelds, D. P. H., Levert, E., Ostendorf, F., Mlačić, B., Blas, L. D., et al. (2010). Only Three Factors of Personality Description Are Fully Replicable across Languages: A Comparison of 14 Trait Taxonomies. J. Personal. Soc. Psychol. 98 (1), 160-173. doi:10.1037/a0017184

DeYoung, C. G., Weisberg, Y. J., Quilty, L. C., and Peterson, J. B. (2013). Unifying the Aspects of the Big Five, the Interpersonal Circumplex, and Trait Affiliation. J. Pers 81 (5), 465-475. doi:10.1111/jopy.12020

Diamond, A. (2013). Executive Functions. Annu. Rev. Psychol. 64 (1), 135-168. doi:10.1146/annurev-psych-113011-143750

Diener, E., Oishi, S., and Lucas, R. E. (2003). Personality, Culture, and Subjective Well-Being: Emotional and Cognitive Evaluations of Life. Annu. Rev. Psychol. 54 (1), 403-425. doi:10.1146/annurev.psych.54.101601.145056

Duckworth, A. L., Peterson, C., Matthews, M. D., and Kelly, D. R. (2007). Grit: Perseverance and Passion for Long-Term Goals. J. Personal. Soc. Psychol. 92 (6), 1087-1101. doi:10.1037/0022-3514.92.6.1087

Duckworth, A. L., and Steinberg, L. (2015). Unpacking Self-Control. Child. Dev. Perspect. 9 (1), 32-37. doi:10.1111/cdep.12107

Duckworth, A. L., and Yeager, D. S. (2015). Measurement Matters. Educ. Res. 44 (4), 237-251. doi:10.3102/0013189X15584327

Durlak, J. A., Weissberg, R. P., Dymnicki, A. B., Taylor, R. D., and Schellinger, K. B. (2011). The Impact of Enhancing Students' Social and Emotional Learning: A Meta-Analysis of School-Based Universal Interventions. Child. Dev. 82 (1), 405-432. doi:10.1111/j.1467-8624.2010.01564.x

Eisenberg, N., Morris, A. S., McDaniel, B., and Spinrad, T. L. (2009). Moral Cognitions and Prosocial Responding in Adolescence. Handbook of Adolescent Psychology: Individual Bases of Adolescent Development. 3rd ed, Vol. 1. John Wiley \& Sons, 229-265. doi:10.1002/ 9780470479193.adlpsy001009

Garcia, N. V., and Scherf, K. S. (2015). Emerging Sensitivity to Socially Complex Expressions: A Unique Role for Adolescence?. Child. Dev. Perspect. 9 (2), 84-90. doi:10.1111/cdep.12114

Glick, G. C., and Rose, A. J. (2011). Prospective Associations between friendship Adjustment and Social Strategies: Friendship as a Context for Building Social Skills. Dev. Psychol. 47 (4), 1117-1132. doi:10.1037/a0023277

Hallal, P. C., Victora, C. G., Azevedo, M. R., and Wells, J. C. K. (2006). Adolescent Physical Activity and Health. Sports Med. 36 (12), 1019-1030. doi:10.2165/ 00007256-200636120-00003

Heckman, J. J., and Kautz, T. (2012). Hard Evidence on Soft Skills. Labour Econ. 19 (4), 451-464. doi:10.1016/j.labeco.2012.05.014

Heckman, J. J., Moon, S. H., Pinto, R., Savelyev, P. A., and Yavitz, A. Q. (2010b). Analyzing Social Experiments as Implemented: A Reexamination of the Evidence from the HighScope Perry Preschool Program. Quantitative Econ. 1 (1), 1-46. doi:10.3982/QE8

Heckman, J. J., Moon, S. H., Pinto, R., Savelyev, P. A., and Yavitz, A. (2010a). The Rate of Return to the HighScope Perry Preschool Program. J. Public Econ. 94 (1-2), 114-128. doi:10.1016/j.jpubeco.2009.11.001

John, O. P., and Soto, C. J. (2007). The Importance of Being Valid: Reliability and the Process of Construct Validation. Handbook of Research Methods in Personality Psychology. The Guilford Press, 461-494.

Kautz, T., Heckman, J. J., Diris, R., ter Weel, B., and Borghans, L. (2014). Fostering and measuring skills: Improving cognitive and non-cognitive skills to promote lifetime success. National Bureau of Economic Research Working Paper 20749. doi:10.3386/w20749

Kautz, T., and Zanoni, W. (2014). Measuring and Fostering Non-cognitive Skills in Adolescence: Evidence from Chicago Public Schools and the OneGoal Program. University of Chicago, Department of Economics. doi:10.3386/ w20749Available at: https://www.issuelab.org/resources/26888/26888.pdf

Keizer, A.-G., Tiemeijer, W., and Bovens, M. (2019). Determinants of Capacity to Act. Why Knowing what to Do Is Not Enough: A Realistic Perspective on Selfreliance. Springer Netherlands, 43-61. doi:10.1007/978-94-024-1725-8_3

Kohlberg, L. (1984). The psychology of moral development. New York: Harper \& Row

Komarraju, M., and Nadler, D. (2013). Self-efficacy and Academic Achievement: Why Do Implicit Beliefs, Goals, and Effort Regulation Matter?. Learn. individual differences 25, 67-72. doi:10.1016/j.lindif.2013.01.005

Kragel, P. A., Zucker, N. L., Covington, V. E., and LaBar, K. S. (2015). Developmental Trajectories of Cortical-Subcortical Interactions Underlying the Evaluation of Trust in Adolescence. Soc. Cogn. Affective Neurosci. 10 (2), 240-247. doi:10.1093/scan/nsu050

Kuhn, D. (2009). Adolescent Thinking. Handbook of Adolescent Psychology: Individual Bases of Adolescent Development. 3rd ed, Vol. 1. John Wiley \& Sons, 152-186. doi:10.1002/9780470479193.adlpsy001007

Lent, R. W., Brown, S. D., and Hackett, G. (2000). Contextual Supports and Barriers to Career Choice: A Social Cognitive Analysis. J. Couns. Psychol. 47 (1), 36-49. doi:10.1037/0022-0167.47.1.36

Lerner, R. M., Lerner, J. V., Almerigi, J. B., Theokas, C., Phelps, E., Gestsdottir, S., et al. (2005). Positive Youth Development, Participation in Community Youth Development Programs, and Community Contributions of Fifth-Grade Adolescents. The J. Early Adolescence 25 (1), 17-71. doi:10.1177/ 0272431604272461

Lewis, M. (1998). Altering Fate: Why the Past Does Not Predict the Future. Psychological Inquiry. 9(2):105-108. doi:10.1207/s15327965pli0902_6New York: The Guilford Press.

Masten, C. L., Eisenberger, N. I., Borofsky, L. A., PfeiferMcNealy, J. H. K., McNealy, K., Mazziotta, J. C., et al. (2009). Neural Correlates of Social Exclusion during Adolescence: Understanding the Distress of Peer Rejection. Soc. Cogn. Affect Neurosci. 4 (2), 143-157. doi:10.1093/scan/nsp007

Matsuba, M. K., Hart, D., and Atkins, R. (2007). Psychological and SocialStructural Influences on Commitment to Volunteering. J. Res. Personal. 41 (4), 889-907. doi:10.1016/j.jp. 2006.11.001

McCrae, R. R., and Costa, P. T., Jr. (1989). More Reasons to Adopt the Five-Factor Model. Am. Psychol. 44 (2), 451-452. doi:10.1037/0003-066X.44.2.451

Mehl, M. R., Gosling, S. D., and Pennebaker, J. W. (2006). Personality in its Natural Habitat: Manifestations and Implicit Folk Theories of Personality in Daily Life. J. Personal. Soc. Psychol. 90 (5), 862-877. doi:10.1037/00223514.90.5.862

Metzger, A., and Smetana, J. G. (2010). Social Cognitive Development and Adolescent Civic Engagement. Handbook of Research on Civic Engagement in Youth. John Wiley \& Sons, 221-248. doi:10.1002/978047076760310.1002/ 9780470767603.ch9

Nagaoka, J., Farrington, C. A., Ehrlich, S. B., and Heath, R. D. (2015). Foundations for Young Adult success: A Developmental Framework. Concept Paper for Research and Practice. In University of Chicago Consortium on Chicago School Research. University of Chicago Consortium on Chicago School Research. . Available at: https://eric.ed.gov/?id=ED559970.

Napolitano, C. M., Bowers, E. P., Gestsdóttir, S., and Chase, P. A. (2011b). "The Development of Intentional Self-Regulation in Adolescence," in Advances in Child Development and Behavior: Positive Youth Development. Editors R. M. Lerner, J. V. Lerner, and J. B. Benson (Academic Press), 19-38. doi:10.1016/b978-0-12-386492-5.00002-6

Napolitano, C. M., Bowers, E. P., Gestsdottir, S., Depping, M., von Eye, A., Chase, P., et al. (2011a). The Role of Parenting and Goal Selection in Positive Youth Development: A Person-Centered Approach. J. Adolescence 34 (6), 1137-1149. doi:10.1016/j.adolescence.2011.07.008

National Research Council (2012). Education for Life and Work: Developing Transferable Knowledge and Skills in the21st century. The National Academies Press.

Noftle, E. E., and Robins, R. W. (2007). Personality Predictors of Academic Outcomes: Big Five Correlates of GPA and SAT Scores. J. Personal. Soc. Psychol. 93 (1), 116-130. doi:10.1037/0022-3514.93.1.116 
Nurmi, J.-E. (2004). Socialization and Self-Development: Channeling, Selection, Adjustment, and Reflection. Handbook of Adolescent Psychology. John Wiley \& Sons, 85-124. doi:10.1002/9780471726746.ch4

Park, D., Tsukayama, E., Goodwin, G. P., Patrick, S., and Duckworth, A. L. (2017). A Tripartite Taxonomy of Character: Evidence for Intrapersonal, Interpersonal, and Intellectual Competencies in Children. Contemp. Educ. Psychol. 48, 16-27. doi:10.1016/j.cedpsych.2016.08.001

Paulhus, D. L., and Martin, C. L. (1987). The Structure of Personality Capabilities. J. Personal. Soc. Psychol. 52 (2), 354-365. doi:10.1037/0022-3514.52.2.354

Pfeifer, J. H., and Blakemore, S.-J. (2012). Adolescent Social Cognitive and Affective Neuroscience: Past, Present, and Future. Soc. Cogn. Affective Neurosci. 7 (1), 1-10. doi:10.1093/scan/nsr099

Pfeifer, J. H., Kahn, L. E., Merchant, J. S., Peake, S. J., Veroude, K., Masten, C. L., et al. (2013). Longitudinal Change in the Neural Bases of Adolescent Social SelfEvaluations: Effects of Age and Pubertal Development. J. Neurosci. 33 (17), 7415-7419. doi:10.1523/JNEUROSCI.4074-12.2013

Poropat, A. E. (2009). A Meta-Analysis of the Five-Factor Model of Personality and Academic Performance. Psychol. Bull. 135 (2), 322-338. doi:10.1037/a0014996

Primi, R., Santos, D., John, O. P., and Fruyt, F. D. (2016). Development of an Inventory Assessing Social and Emotional Skills in Brazilian Youth. Eur. J. Psychol. Assess. 32 (1), 5-16. doi:10.1027/1015-5759/a000343

Roberts, B. W., and Mroczek, D. (2008). Personality Trait Change in Adulthood. Curr. Dir. Psychol. Sci. 17 (1), 31-35. doi:10.1111/j.14678721.2008.00543.x

Ryan, A. M., and Shin, H. (2018). "Peers, Academics, and Teachers," in Handbook of Peer Interactions, Relationships and Groups. Editors W. B. Bukowski, B. Laursen, and K. H. Rubin (New York: Guilford Press), 637-646.

Sackett, P. R., Zedeck, S., and Fogli, L. (1988). Relations between Measures of Typical and Maximum Job Performance. J. Appl. Psychol. 73 (3), 482-486. doi:10.1037/0021-9010.73.3.4810.1037/0021-9010.73.3.482

Salmela-Aro, K. (2009). Personal Goals and Well-Being during Critical Life Transitions: The Four C's-Channelling, Choice, Co-agency and Compensation. Adv. Life Course Res. 14 (1-2), 63-73. doi:10.1016/ j.alcr.2009.03.003

Saucier, G., and Goldberg, L. R. (2001). Lexical Studies of Indigenous Personality Factors: Premises, Products, and Prospects. J. Personal. 69 (6), 847-879. doi:10.1111/1467-6494.696167

Schmitt, D. P., Allik, J., McCrae, R. R., and Benet-Martínez, V. (2007). The Geographic Distribution of Big Five Personality Traits. J. Cross-Cultural Psychol. 38 (2), 173-212. doi:10.1177/0022022106297299

Scorza, P., Araya, R., Wuermli, A. J., and Betancourt, T. S. (2016). Towards Clarity in Research on "Non-cognitive" Skills: Linking Executive Functions, SelfRegulation, and Economic Development to Advance Life Outcomes for Children, Adolescents and Youth Globally. Hum. Dev. 58 (6), 313-317. doi:10.1159/000443711

Shiner, R. L., and DeYoung, C. G. (2013). The Structure of Temperament and Personality Traits: A Developmental Perspective. The Oxford Handbook of Developmental Psychology, Vol. 2. (pp. 113-141). Oxford University Press.
Smetana, J. G., and Villalobos, M. (2009). Social Cognitive Development in Adolescence. Handbook of Adolescent Psychology: Individual Bases of Adolescent Development. 3rd ed, Vol. 1. John Wiley \& Sons, 187-228. doi:10.1002/9780470479193.adlpsy001008

Soto, C. J., Napolitano, C. M., and Roberts, B. W. (2021b). Taking Skills Seriously: Toward an Integrative Model and Agenda for Social, Emotional, and Behavioral Skills. Curr. Dir. Psychol. Sci. 30 (1), 26-33. doi:10.1177/0963721420978613

Soto, C. J., Napolitano, C., Sewell, M. N., Yoon, H. R., and Roberts, B. (2021a). An Integrative Framework for Conceptualizing and Assessing Social, Emotional, and Behavioral Skills: The BESSI. The BESSI. doi:10.31234/osf.io/8m $34 \mathrm{z}$

Soto, C. J., and Tackett, J. L. (2015). Personality Traits in Childhood and Adolescence. Curr. Dir. Psychol. Sci. 24 (5), 358-362. doi:10.1177/ 0963721415589345

Taylor, R. D., Oberle, E., Durlak, J. A., and Weissberg, R. P. (2017). Promoting Positive Youth Development through School-Based Social and Emotional Learning Interventions: A Meta-Analysis of Follow-Up Effects. Child. Dev. 88 (4), 1156-1171. doi:10.1111/cdev.12864

Turner, R. G. (1978). Consistency, Self-Consciousness, and the Predictive Validity of Typical and Maximal Personality Measures. J. Res. Personal. 12, 117-132. doi:10.1016/0092-6566(78)90088-0

Vazire, S. (2006). Informant Reports: A Cheap, Fast, and Easy Method for Personality Assessment. J. Res. Personal. 40 (5), 472-481. doi:10.1016/ j.jrp.2005.03.003

Wallace, J. (1966). An Abilities conception of Personality: Some Implications for Personality Measurement. Am. Psychol. 21, 132-138. doi:10.1037/h0023298

Wallace, J. (1967). What Units Shall We Employ? Allport's Question Revisited. J. Consulting Psychol. 31 (1), 56-64. doi:10.1037/h0024208

Wilmot, M. P., and Ones, D. S. (2019). A century of Research on Conscientiousness at Work. Proc. Natl. Acad. Sci. USA 116 (46), 23004-23010. doi:10.1073/ pnas. 1908430116

Wilt, J., and Revelle, W. (2015). Affect, Behaviour, Cognition and Desire in the Big Five: An Analysis of Item Content and Structure. Eur. J. Pers 29 (4), 478-497. doi:10.1002/per.2002

Wray-Lake, L., Syvertsen, A. K., and Flanagan, C. A. (2016). Developmental Change in Social Responsibility during Adolescence: An Ecological Perspective. Dev. Psychol. 52 (1), 130-142. doi:10.1037/dev0000067

Conflict of Interest: The authors declare that the research was conducted in the absence of any commercial or financial relationships that could be construed as a potential conflict of interest.

Copyright (c) 2021 Napolitano, Sewell, Yoon, Soto and Roberts. This is an open-access article distributed under the terms of the Creative Commons Attribution License (CC $B Y)$. The use, distribution or reproduction in other forums is permitted, provided the original author(s) and the copyright owner(s) are credited and that the original publication in this journal is cited, in accordance with accepted academic practice. No use, distribution or reproduction is permitted which does not comply with these terms. 